\title{
Assessment of sagittal spinopelvic parameters in a Taiwanese population with spondylolysis by the EOS imaging system: a retrospective radiological analysis
}

Hao-Chun Chuang ${ }^{1}$ (D), Yu-Hsiang Tseng ${ }^{2}$, Yueh Chen ${ }^{3}$ (D), Po-Hsin Chou ${ }^{4} \mathbb{D}$, Wei-Lun Chang ${ }^{1,5}$, Pei-Fang Su ${ }^{6}$ and Cheng-Li Lin ${ }^{1,7,8,9^{*}}$ (D)

\begin{abstract}
Background: The impact of sagittal spinopelvic alignment on spondylolysis is well established in Caucasian populations. However, prior studies suggest that people from different ethnological backgrounds showed divergence, and a few studies that focused on Asian populations reported conflicting results. The aim of this study is to use the EOS imaging system to evaluate the spinopelvic parameters of spondylolysis patients, and their relationship with spondylolisthesis, disc degeneration, and age in a Taiwanese population.

Methods: Radiographic sagittal spinopelvic parameters for 45 spondylolysis patients and 32 healthy people were evaluated, including pelvic incidence (PI), sacral slope (SS), pelvic tilt (PT), thoracic kyphosis (TK), and lumbar lordosis (LL). The spinopelvic parameters were compared between spondylolytic and control groups. These parameters were further compared between spondylolytic subjects with and without spondylolisthesis, with and without high-grade disc degeneration, and young $(<30$ years old) and middle-aged.

Results: The PI and $\mathrm{LL}$ of the spondylolytic group $\left(52.6^{\circ} \pm 12.0^{\circ}\right.$ and $\left.41.3^{\circ} \pm 15.2^{\circ}\right)$ were significantly higher than those of the healthy control group $\left(47.16^{\circ} \pm 7.95^{\circ}\right.$ and $\left.28.22^{\circ} \pm 10.65^{\circ}\right)$. Further analysis of the spondylolytic patients revealed that those with high-grade disc degeneration were more prone to spondylolisthesis ( $92.3 \%$ ) compared to those without ( $50 \% ; p=0.001$ ). The middle-aged group had significantly higher rates of spondylolisthesis $(80 \%)$ and high-grade disc degeneration (52.4\%) compared with those for the young group (45 and $16.7 \%$, respectively; $p=0.017$ and 0.047 , respectively). No statistically significant difference in the sagittal spinopelvic parameters was found when spondylolytic patients were divided according to the occurrence of spondylolisthesis or high-grade disc degeneration.
\end{abstract}

\footnotetext{
* Correspondence: jengli94@gmail.com

'Department of Orthopaedic Surgery, National Cheng Kung University Hospital, College of Medicine, National Cheng Kung University, No.138, Sheng-Li Road, 70428 Tainan, Taiwan

${ }^{7}$ Skeleton Materials and Bio-compatibility Core Lab, Research Center of Clinical Medicine, College of Medicine, National Cheng Kung University Hospital, National Cheng Kung University, Tainan, Taiwan

Full list of author information is available at the end of the article
}

C C The Author(s). 2021 Open Access This article is licensed under a Creative Commons Attribution 4.0 International License, which permits use, sharing, adaptation, distribution and reproduction in any medium or format, as long as you give appropriate credit to the original author(s) and the source, provide a link to the Creative Commons licence, and indicate if changes were made. The images or other third party material in this article are included in the article's Creative Commons licence, unless indicated otherwise in a credit line to the material. If material is not included in the article's Creative Commons licence and your intended use is not permitted by statutory regulation or exceeds the permitted use, you will need to obtain permission directly from the copyright holder. To view a copy of this licence, visit http://creativecommons.org/licenses/by/4.0/ The Creative Commons Public Domain Dedication waiver (http://creativecommons.org/publicdomain/zero/1.0/) applies to the data made available in this article, unless otherwise stated in a credit line to the data. 
Conclusions: In a Taiwanese population, PI and LL were significantly larger in spondylolytic patients. Disc degeneration and age were associated with the occurrence of spondylolisthesis. Ethnological differences should thus be taken into account when making clinical decisions regarding spondylolysis in a Taiwanese population.

Keywords: Radiography, Spinopelvic parameter, Spinopelvic alignment, Spondylolysis, Spondylolisthesis

\section{Introduction}

Spondylolysis refers to a defect of the vertebral pars interarticularis. It can result in vertebral slippage relative to the adjacent vertebrae, a condition called spondylolisthesis. The pathogenesis of spondylolysis and spondylolisthesis was believed to involve sagittal spinopelvic alignment [1]. For example, an increase in pelvic incidence (PI) is correlated with lumbar lordosis in spondylolysis patients compared with healthy people [1-5] Also, the increase in PI is also correlated with an increasing slip grade in spondylolisthesis patients $[4,6-9]$. Another common pathological change in spondylolysis patient is intervertebral disc (IVD) degeneration below the lytic level [10]. Some authors have concluded that the grade of slippage is positively correlated with spinopelvic parameters such as PI, sacral slope (SS), and lumbar lordosis (LL) in spondylolisthesis patients [11]. However, published studies focus mostly on Western populations. The few studies addressing the Eastern populations reported conflicting results [11-14].

Published studies used computed radiography (CR) or digital radiography (DR) to evaluate the spinopelvic parameters, spondylolisthesis, and spondylolysis. CR and DR systems project information on the image plane through a conic perspective. This causes distortion from the center to the edges of the radiograph, increasing errors in scale for structures far from the central region [15]. The EOS imaging system, a slot-scanning radiograph imager, overcomes this problem by allowing the acquisition of whole-body radiograph images while the patient is in a weight-bearing position. It provides spinopelvic parameters and the degree of spondylolisthesis under physiological conditions similar to those of daily life.

To the best of our knowledge, no previous study used the EOS imaging system to assess the spinopelvic parameters in Eastern population. Thus, the aim of this study is to use the EOS imaging system to evaluate the spinopelvic parameters of spondylolysis patients, and their relationship with spondylolisthesis, disc degeneration, and age in a Taiwanese population.

\section{Materials and methods}

Patients who visited our orthopedic clinic from December 2017 to June 2018 were included in this study. A total of 45 individuals complaining of low back pain and diagnosed with spondylolysis composed the spondylolytic group, while 32 asymptomatic individuals coming for conscription physical examination composed the control group. Plain radiography and computed tomography (CT) were used to confirm the diagnosis of spondylolysis. Imaging examinations undergone by the 77 patients, including radiography, EOS examination, and CT were clustered within an interval of one month. MRI performed in 33 of the 45 individuals with low back pain was analyzed as well. The images were examined and reported by boardcertified musculoskeletal radiologists in NCKUH. Exclusion criteria for this study included patients with dysplastic, degenerative, or pathological spondylolisthesis, unilateral lysis, lumbosacral transitional vertebra, scoliosis, Scheuermann disease, hip pathology, and unidentifiable femoral heads on lateral radiographs. The gender, age, level of spondylolysis, degree of slip, degree of disc degeneration below the level of spondylolysis, and spinopelvic parameters were documented.

This research study was conducted retrospectively from data obtained for clinical purposes. We consulted extensively with the IRB of National Cheng Kung University Hospital who determined that our study did not need ethical approval or informed consent. An IRB official waiver of ethical approval was granted from the IRB of National Cheng Kung University Hospital. (No. B-ER-106-210)

\section{Radiographic Spinopelvic Parameters}

Biplanar radiographs in a standing position were taken using the EOS imaging system (EOS Imaging). The subjects stood in a standardized erect posture, with knees and hips fully extended, shoulder anteriorly flexed by $90^{\circ}$, elbow extended, and hands resting on a support handle. Images were captured with minimal magnification and distortion as the system employs line detection of double-collimated X-ray beams. All radiographic parameters were measured by a senior orthopedist using the picture archiving and communication systems (PACS) software. The usefulness of these spinopelvic parameters were verified in previous studies by Tyrakowski et al. [16-18].

The following radiographic spinopelvic parameters were calculated (Figs. 1 and 2):

- Pelvic incidence (PI): the angle between the line perpendicular to the sacral endplate and the line connecting the midpoint of the femoral heads to the midpoint of sacral plate [9]. 


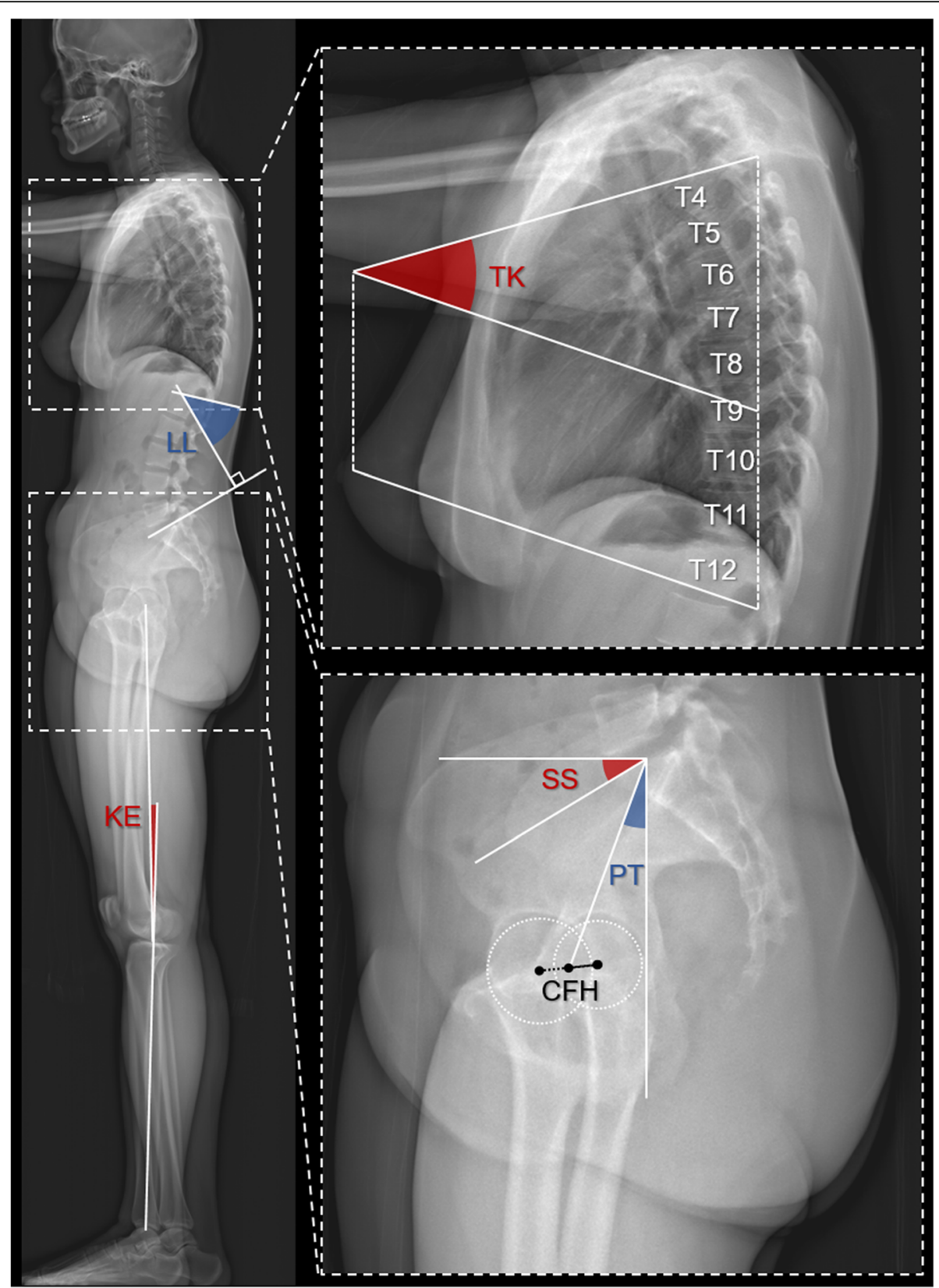

Fig. 1 The graph shows how sagittal spinopelvic parameters were measured. PI = PT + SS. TK, thoracic kyphosis; PI, pelvic incidence; PT, pelvic tilt; $\mathrm{SS}$, sacral slope; CFH, center of femoral heads; LL, lumbar lordosis; KE, knee extension

- Sacral slope (SS): the angle between the horizontal plane and the line tangent to the sacral endplate [9].

- Pelvic tilt (PT): the angle between the vertical line and the line connecting the midpoint of sacral endplate to the midpoint of the femoral heads, namely the anterior pelvic plane (APP) [9].

- Thoracic kyphosis (TK): the angle between the cranial T4 endplate and caudal T12 endplate [19, 20].

- Lumbar lordosis (LL): the angle between the cranial L1 endplate and the cranial sacral endplate [9].
- Sagittal vertical axis (SVA): the shortest distance between the posterosuperior corner of $\mathrm{S} 1$ and the C7 plumb line, which is the vertical line through the center of the $\mathrm{C} 7$ vertebral body [21]. (Fig. 2)

- Center of acoustic meatus (CAM) plumb line: the distance between the plumb line through CAM and the $\mathrm{C} 7$ plumb line.

- T1 tilt (T1t): the angle between the line tangent to the cranial endplate of $\mathrm{T} 1$ and a horizontal line.

- T9 tilt (T9t): the angle between the line tangent to the cranial endplate of T9 and a horizontal line. 


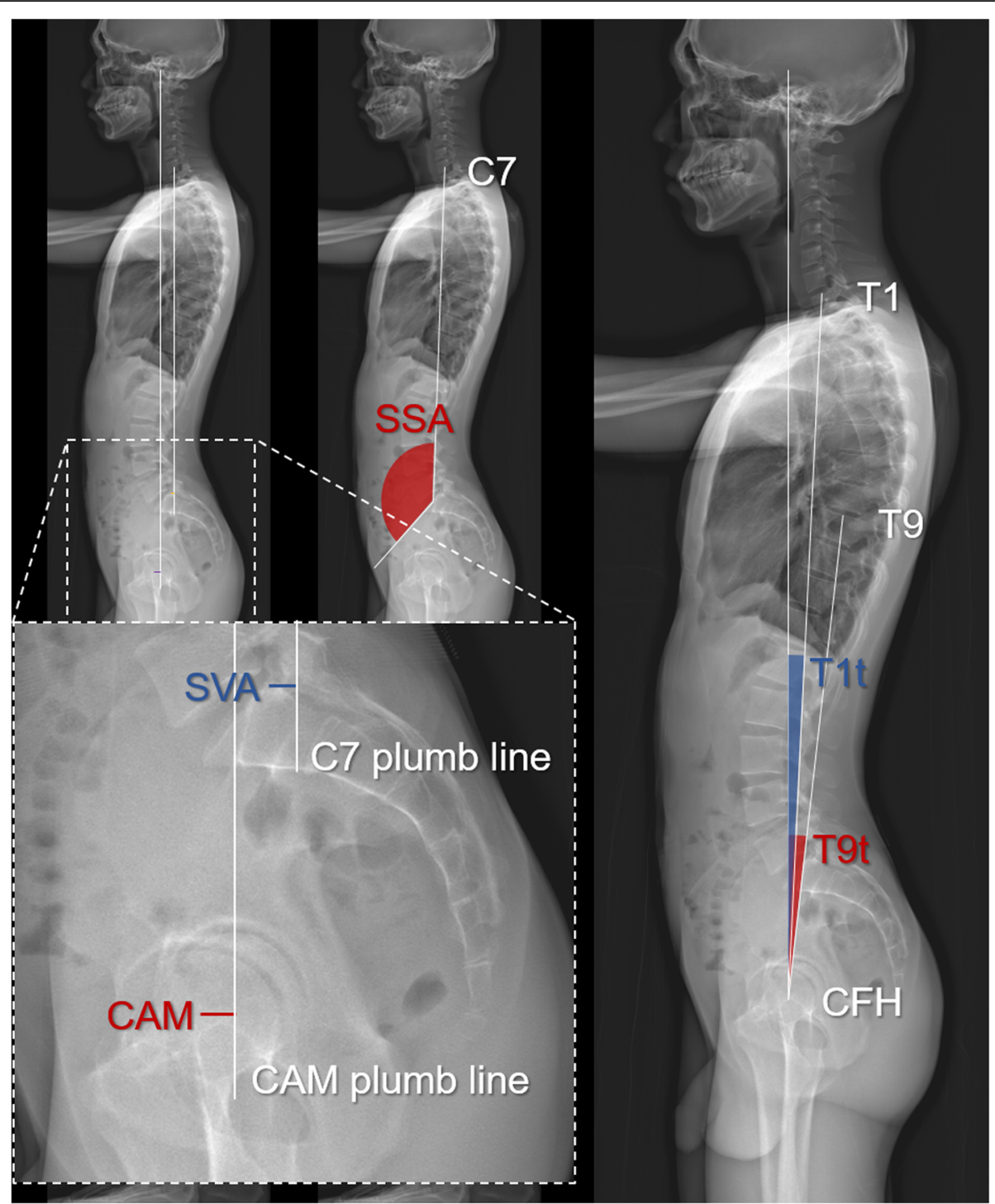

Fig. 2 The graph shows how whole-body sagittal spinopelvic parameters were measured. SVA, sagittal vertical axis; CAM, center of acoustic meatus; SSA, spino-sacral angle; T1t, T1 tilt; T9t, T9 tilt; CFH, center of femoral heads

- Spinosacral angle (SSA): the angle between the line connecting the center of the $\mathrm{C} 7$ vertebral body to the midpoint of the cranial sacral endplate and the line tangent to the cranial sacral endplate.

- Knee extension (KE): the angle between the axis of femur and that of the tibia (Fig. 1). The average of bilateral angles was used in statistical analysis.

\section{Analysis of Subgroups}

The radiographic spinopelvic parameters of patients with spondylolysis and those of the control group were compared. The spondylolytic group was further divided according to the degree of spondylolisthesis, disc degeneration, and age.
First, the spondylolytic group was dichotomized according to the presence of spondylolisthesis. The spinopelvic parameters of the spondylolisthetic spondylolysis group and the simple spondylolysis group were analyzed.

Second, the IVD immediately inferior to the spondylolytic segment was assessed. Degeneration of the discs was graded according to the modified Pfirrmann classification on MRI images [22]. Patients with grade I, II, or III disc degeneration on the modified Pfirrmann classification were defined as having no highgrade degeneration, and those with grade IV or $\mathrm{V}$ disc degeneration were defined as having high-grade degeneration. The spinopelvic parameters for the lowand high-grade groups were compared. 
Finally, the spondylolytic group was divided into a young group and a middle-aged group using an age of 30 years as the cutoff value. The division of age by 30 was based on a study conducted by Floman et al. in an Israeli population, who observed that spondylolisthesis tended to progress in the third decade of life [23].

\section{Statistical analysis}

The spinopelvic parameters for the spondylolytic group and the control group were compared using the independent two-sample $t$-test. For subgroup analyses assessing the impact of spondylolisthesis, high-grade disc degeneration, and age, the Mann-Whitney $U$ test was adopted. When comparing the grade of disc degeneration and the occurrence of spondylolisthesis between the young and middle-aged groups, Fisher's exact test was used because the expected values in one of the cells were below 5. The level of significance was set at 0.05 $(\mathrm{p}<0.05)$. All statistical analyses were performed using SPSS 17 (SPSS Inc., Chicago, Illinois).

\section{Results}

The demographic data of the two groups are shown in Table 1. The mean age of the spondylosis group was higher than that of the control group.

\section{Analysis of spinopelvic parameters}

Among the parameters, PI, LL, and KE were significantly higher in the spondylolysis group compared to those in the control group (Table 2). PI was $52.59 \pm 11.6^{\circ}$ in the spondylolysis group and $47.16 \pm 7.95^{\circ}$ in the control group $(p<0.05)$. LL was $41.51 \pm 14.11^{\circ}$ in the spondylolysis group and $28.22 \pm 10.65^{\circ}$ in the control group $(p<0.05)$. KE was $3.48 \pm 2.14^{\circ}$ in the spondylolysis group and $1.87 \pm 4.48^{\circ}$ in the control group $(p<0.01)$. In spondylolysis participants, there was no statistically significant difference in the measured spinopelvic parameters between slip and no slip (Table 3), nor between male and female subjects.

\section{Presence of high-grade intervertebral disc degeneration} Thirty-three spondylolysis participants received MRI examinations to assess the degree of disc degeneration. PI in those without high-grade IVD degeneration group was lower $\left(50.54 \pm 10.7^{\circ}\right)$ compared to that in the high-

Table 1 Demographics of the study population

\begin{tabular}{lll}
\hline & Spondylolysis group & Control group \\
\hline Number (n) & 45 & 32 \\
Mean age (years) & $34.9 \pm 14.1$ & $22.5 \pm 4.2$ \\
Male (n, \%) & $35(78 \%)$ & $28(87 \%)$ \\
Lysis level (n) & L5 (40), L4 (5) & 0 \\
Slip grade (n) & $0(16)$, I (27), II (2) & 0 \\
IVD (n) & I (4), II (8), III (8), IV (11), V (2) & 0 \\
\hline
\end{tabular}

grade group $\left(58.38 \pm 12.65^{\circ}\right)$, though it did not reach a statistically significant difference $(p=0.087)$. There were no statistically significant differences between individuals with and without high-grade disc degeneration in all other parameters (Table 4). There was significantly more spondylolisthesis noted in high-grade IVD (92.3\%) compared to that in those without high-grade IVD (50\%) $(p<0.01)$.

\section{Parameters for young and middle-aged participants}

There were no statistically significant differences in spinopelvic parameters between these two groups. The occurrence of spondylolisthesis was significantly higher in the middle-aged group ( $80 \%)$ than that in the young group (45\%) $(p<0.05)$ (Table 5). Among the 33 individuals (out of the 45 patients with low back pain) who underwent MRI examinations, a higher degree of IVD degeneration was found in the middle-aged group $(52.4 \%)$ compared with the young group $(16.7 \%)$ with a statistically significant difference $(p<0.05)$ (Table 6).

\section{Discussion}

Sagittal spinopelvic alignment has a profound impact on the biomechanics of the spine and environment and is of central importance in the pathogenesis of spondylolysis and spondylolisthesis. In the present study, PI, LL, and KE were significantly higher in spondylolytic individuals compared to healthy people. The patients with highgrade disc degeneration were more prone to spondylolisthesis $(92.3 \%)$ compared to those without (50\%). Spondylolytic patients older than 30 years old were also more prone to spondylolisthesis $(80 \%)$ and high-grade disc degeneration (52.4\%) compared to those younger than 30 years old ( 45 and $16.7 \%$, respectively). No significant difference in sagittal spinopelvic parameters was found when spondylolytic individuals were subdivided according to the presence of spondylolisthesis or highgrade disc degeneration.

It is well established that spinopelvic parameters of healthy individuals are, at least in part, associated with ethnic background. Zhu et al. compared healthy subjects from a Chinese Han population with age-matched controls from a Caucasian population. The PI and SS reported for the Chinese individuals, $44.6^{\circ}$ and $32.5^{\circ}$, were significantly smaller than those for the Caucasian ones, $52.6^{\circ}$ and $39.6^{\circ}$, respectively [22]. Interestingly, healthy young individuals from different Asian countries differ as well. A healthy control group from a Korean population had PI and SS of $45.8^{\circ}$ and $29.3^{\circ}$, respectively [12], with the latter being somewhat smaller than that of a Chinese population. In the healthy control group of the current study, PI was $47.16^{\circ}$ and SS was $37.91^{\circ}$, which are larger than those for other Asian individuals but smaller than those for Caucasian people according to 
Table 2 Parameters for spondylolysis and control groups

\begin{tabular}{|c|c|c|c|c|c|c|c|c|c|c|c|c|}
\hline & & $\mathrm{PI}\left({ }^{\circ}\right)$ & SS $\left(^{\circ}\right)$ & PT $\left(^{\circ}\right)$ & LL $\left(^{\circ}\right)$ & TK $\left(^{\circ}\right)$ & SVA $(\mathrm{mm})$ & CAM (mm) & T1t $\left(^{\circ}\right)$ & T9t $\left({ }^{\circ}\right)$ & SSA $\left(^{\circ}\right)$ & $\mathrm{KE}\left({ }^{\circ}\right)$ \\
\hline Healthy control & Mean & 47.16 & 37.91 & 9.47 & 28.22 & 34.50 & 9.94 & -7.56 & 2.56 & 7.56 & 128.31 & 1.87 \\
\hline$n=32$ & SD & 7.95 & 7.55 & 7.01 & 10.65 & 7.56 & 27.69 & 35.03 & 3.00 & 3.25 & 9.29 & 4.48 \\
\hline Spondylolysis & Mean & 52.59 & 41.38 & 11.17 & 41.34 & 31.62 & 20.07 & -5.48 & 2.04 & 6.48 & 130.33 & 3.48 \\
\hline$n=45$ & SD & 11.60 & 8.74 & 6.66 & 14.11 & 10.98 & 25.77 & 23.46 & 2.14 & 3.62 & 9.53 & 2.14 \\
\hline$p$ value & & $0.042^{*}$ & 0.123 & 0.279 & $0.040^{*}$ & 0.126 & 0.658 & 0.626 & 0.866 & 0.614 & 0.342 & $0.001^{*}$ \\
\hline
\end{tabular}

SVA sagittal vertical axis; CAM center of acoustic meatus; T1t T1 tilt; T9t T9 tilt; SSA spinal-sacral angle; KE knee extension * $P<0.05$ was defined as statistically significant

statistics from previous studies $[1,14,19,24-28]$. When making clinical decisions in a Taiwanese population, which has a diverse genetic background [29], extra caution should be taken if studies that focused on a nonTaiwanese ethnic group are referred to. To sum up, there are differences in spinopelvic alignment not only between Asian and Caucasian people but also among different ethnic groups in Asia.

The association between spinopelvic alignment and spondylolysis has been discussed in recent years. However, most studies considered only a Caucasian population, and the few studies that focused on an Asian population yielded inconsistent results. Among Caucasian patients, many studies found that PI and LL are larger among spondylolytic patients than among healthy individuals $[1-3,27]$, where both PT and SS were reportedly larger in spondylolysis patients in some of these studies $[2,27]$. Yin et al. reported comparable results in a Chinese Han population, stating that PI, PT, SS, and LL of spondylolytic patients were all significantly higher than those of the healthy control group [9]. However, Oh et al. reported that only PI and SS were higher among Korean spondylolytic patients, while PT and LL did not differ significantly from those of healthy Koreans [12]. Among Taiwanese spondylolytic patients included in the current study, PI, LL, and SS were larger than those for the control group, though the last did not reach statistical significance. PT did not differ significantly from the control group. Our results are consistent with previous studies. Stagnara et al. proposed that LL increases linearly with SS and that the elevation in LL is to maintain overall balance [30-32]. The sameness of PT in our study could be partially accounted for by the theory of Oh et al., who illustrated that a compensatory mechanism such as PT did not occur until advanced age [12]. Notably, the control group showed slight mismatch of spinopelvic harmony, which was also found in a previous study on the Korean population [12]. It is possible that the range of spinopelvic harmony is slightly larger in the Asian population, but the speculation will require a larger population to confirm. Interestingly, the present study is the first to report that KE is increased in spondylolytic patients. Though the impact of $\mathrm{KE}$ angle on lower lumbar pathologies may not be substantial, the increase in KE may suggest one of the compensatory mechanisms after the incidence of spondylolysis. To conclude, the current study clarifies the association between spinopelvic alignment and spondylolysis in a Taiwanese population.

Parameters such as PI have been shown to increase in Caucasian patients with advanced isthmic spondylolisthesis $[4,6]$. However, conflicting results have been observed in Asian populations. For patients with and without spondylolisthesis, Yin et al. did not report any difference in the sagittal lumbosacral parameters whereas $\mathrm{Oh}$ et al. identified an increase in PI, SS, and LL as spondylolisthesis progressed $[9,13]$. In the present study, PI and LL were comparable in spondylolytic patients with and without slippage, which supports the distinction between Caucasian and Asian spinopelvic alignment. Interestingly, substantial but statistically insignificant increases in SVA were observed in spondylolytic patients, and further increases were found for patients with spondylolisthesis. Limited by the scope of conventional radiography, previous studies could not probe into the global indices of the

Table 3 Parameters for spondylolysis patients with and without spondylolisthesis

\begin{tabular}{|c|c|c|c|c|c|c|c|c|c|c|c|c|}
\hline & & $\mathrm{PI}\left({ }^{\circ}\right)$ & SS $\left(^{\circ}\right)$ & PT $\left({ }^{\circ}\right)$ & LL $\left(^{\circ}\right)$ & TK $\left(^{\circ}\right)$ & SVA (mm) & CAM (mm) & T1t $\left(^{\circ}\right)$ & T9t $\left(^{\circ}\right)$ & SSA $\left(^{\circ}\right)$ & KE $\left(^{\circ}\right)$ \\
\hline Spondylolisthesis (-) & Mean & 49.81 & 40.31 & 9.68 & 41.56 & 32.43 & 12.66 & -8.91 & 2.41 & 7.16 & 130.75 & 3.58 \\
\hline$n=16$ & SD & 11.57 & 10.05 & 5.57 & 14.29 & 7.15 & 12.98 & 17.85 & 1.31 & 2.08 & 11.61 & 2.64 \\
\hline Spondylolisthesis (+) & Mean & 53.37 & 41.27 & 11.96 & 41.48 & 30.86 & 19.40 & -9.40 & 2.36 & 7.00 & 129.45 & 3.50 \\
\hline$n=29$ & SD & 11.62 & 8.10 & 7.15 & 12.69 & 14.27 & 30.17 & 29.08 & 2.53 & 4.16 & 7.99 & 2.46 \\
\hline$P$ value & & 0.553 & 0.831 & 0.285 & 0.313 & 0.943 & 0.736 & 0.986 & 0.958 & 0.736 & 0.582 & 0.873 \\
\hline
\end{tabular}

SVA sagittal vertical axis; CAM center of acoustic meatus; T1t T1 tilt; T9t T9 tilt; SSA spinal-sacral angle; KE knee extension 
Table 4 Parameters for high-grade and those without high-grade intervertebral disc degeneration in spondylolysis patients

\begin{tabular}{|c|c|c|c|c|c|c|c|c|c|c|c|c|c|}
\hline $\begin{array}{l}\text { Condition of IVD } \\
\text { degeneration }\end{array}$ & $\begin{array}{l}\text { Prevalence of } \\
\text { Spondylolisthesis }\end{array}$ & & PI ( $\left.{ }^{\circ}\right)$ & SS $\left(^{\circ}\right)$ & PT $\left(^{\circ}\right)$ & LL $\left(^{\circ}\right)$ & TK $\left(^{\circ}\right)$ & SVA (mm) & CAM (mm) & T1t $\left(^{\circ}\right)$ & T9t $\left(^{\circ}\right)$ & SSA $\left(^{\circ}\right)$ & $\mathrm{KE}\left({ }^{\circ}\right)$ \\
\hline No High-grade & $50 \%(10 / 20)^{a}$ & Mean & 50.45 & 41.15 & 9.40 & 42.20 & 29.65 & 7.80 & -16.80 & 2.93 & 6.80 & 131.60 & 3.06 \\
\hline$n=20$ & & SD & 10.70 & 8.75 & 5.68 & 13.04 & 8.84 & 17.05 & 16.40 & 1.66 & 3.14 & 9.46 & 2.40 \\
\hline High-grade & $92.3 \%(12 / 13)^{b}$ & Mean & 58.38 & 44.15 & 14.15 & 47.07 & 36.30 & 23.09 & -9.18 & 2.54 & 8.27 & 131 & 3.45 \\
\hline$n=13$ & & SD & 12.65 & 8.07 & 8.02 & 16.38 & 14.42 & 30.65 & 32.04 & 2.38 & 3.16 & 7.57 & 2.38 \\
\hline$P$ value & $0.001^{*}$ & & 0.087 & 0.334 & 0.110 & 0.501 & 0.221 & 0.164 & 0.610 & 0.507 & 0.413 & 0.760 & 0.507 \\
\hline
\end{tabular}

IVD intervertebral disc; SVA sagittal vertical axis; CAM center of acoustic meatus; T1t T1 tilt; T9t T9 tilt; SSA spinal-sacral angle; KE knee extension

${ }^{*} P<0.05$ was defined as statistically significant

a All of the 10 patients had grade 1 spondylolisthesis, according to the meyerding classification

${ }^{a}$ Of the 12 patients, 10 had grade 1 and 2 had grade 2 spondylolisthesis

body. The increase in SVA reflects that the center of gravity is shifted anteriorly in spondylolytic Taiwanese patients, and that this condition is exacerbated when spondylolisthesis occurs. In brief, Taiwanese patients with isthmic spondylolisthesis have comparable PI to that of the control group but their center of gravity drifts anteriorly.

The IVD is one of the major contributors to spine stability. When a vertebra slips anteriorly, the IVD is wedged and thus the LL increases to compensate for the shift of the center of gravity [28]. It is known that the disc immediately inferior to the spondylolytic level is prone to high-grade degeneration [10,33-35]. Our results are consistent with this observation, demonstrating that high-grade disc degeneration is associated with spondylolisthesis while low-grade disc degeneration is not. This implies that without the stabilizing force from a healthy disc, the anterior sliding of isthmic spondylolisthesis could be intractable. Our study is consistent with the literature, confirming the major role of the IVD in spinal stability.

IVD degeneration is a complicated process, involving tissue damage and many age-related changes [36]. In addition, spondylolysis itself is a risk factor for disc degeneration, with approximately $15 \%$ of spondylolytic patients eventually progressing to spondylolisthesis [37]. In the Taiwanese population in our study, patients in the middle-aged group were apt to have a higher degree of spondylolisthesis and a higher grade of disc degeneration. This finding is consistent with the natural course of spondylolysis; the percentage of spondylolisthesis and the grade of disc degeneration are expected to increase with age [38]. Hence, more attention should be paid to middle-aged Taiwanese spondylolytic patients. The follow-up interval should be shortened compared the length suggested in western literature, and back braces may be considered.

The EOS imaging system is one of the most pragmatic approaches for investigating spinopelvic parameters. Previous studies revealed that the EOS system can examine the whole body in a physiological stance and produce high-resolution images with little distortion while avoiding the high radiation dose associated with taking many conventional radiographs at once [15, 39]. These features allowed us to evaluate whole-body indices such as SVA. The EOS imaging system also provides highquality lateral images of the pelvic girdle and lower extremities, which are difficult to obtain using conventional X-ray techniques [40]. The system thus allows clinicians to assess pelvic parameters in a reliable and reproducible manner. To the best of our knowledge, this is the first study to use the EOS imaging system for investigating radiographic parameters in individuals with spondylolysis. The present study demonstrated the consistency and reproducibility of EOS images.

There are several limitations of the current study. First, the cross-sectional rather than longitudinal design precluded the recognition of disease progression and the exact point in time of the occurrence of spondylolysis. Second, the sample size of our study may not be large

Table 5 Parameters for young and middle-aged participants

\begin{tabular}{|c|c|c|c|c|c|c|c|c|c|c|c|c|c|}
\hline Age (years) & $\begin{array}{l}\text { Prevalence of } \\
\text { Spondylolisthesis }\end{array}$ & & $\mathrm{PI}\left({ }^{\circ}\right)$ & SS $\left(^{\circ}\right)$ & PT $\left({ }^{\circ}\right)$ & $\operatorname{LL}\left({ }^{\circ}\right)$ & TK $\left(^{\circ}\right)$ & SVA (mm) & CAM $(\mathrm{mm})$ & T1t $\left(^{\circ}\right)$ & T9t $\left(^{\circ}\right)$ & SSA $\left(^{\circ}\right)$ & KE $\left(^{\circ}\right)$ \\
\hline$<30$ & $45 \%$ & Mean & 50.40 & 39.75 & 10.60 & 39.85 & 30.40 & 13.26 & -6.66 & 2.53 & 6.80 & 128.93 & 3.33 \\
\hline$n=20$ & & SD & 10.59 & 9.78 & 5.21 & 14.95 & 8.71 & 13.81 & 19.41 & 1.68 & 3.32 & 10.11 & 2.52 \\
\hline$>30$ & $80 \%$ & Mean & 53.48 & 41.88 & 11.60 & 42.84 & 32.24 & 20.00 & -11.2 & 2.26 & 7.26 & 130.68 & 3.68 \\
\hline$n=25$ & & SD & 12.39 & 7.89 & 7.70 & 13.57 & 12.62 & 31.86 & 29.64 & 2.51 & 3.76 & 8.75 & 2.51 \\
\hline$P$ value & $0.017^{*}$ & & 0.664 & 0.598 & 0.748 & 0.458 & 0.900 & 0.732 & 0.560 & 0.681 & 0.758 & 0.758 & 0.632 \\
\hline
\end{tabular}

IVDintervertebral disc; SVA sagittal vertical axis; CAM center of acoustic meatus; T1t T1 tilt; T9t T9 tilt; SSA spinal-acral angle; KE knee extension

${ }^{*} P<0.05$ was defined as statistically significant 
Table 6 Disc degeneration in young and middle-aged participants

\begin{tabular}{lll}
\hline & $\begin{array}{l}\text { No high-grade disc } \\
\text { degeneration }\end{array}$ & $\begin{array}{l}\text { High-grade disc } \\
\text { degeneration }^{\mathbf{a}}\end{array}$ \\
\hline Age $<30$ & 10 & 2 \\
Age $>30$ & 10 & 11 \\
\hline
\end{tabular}

$P=0.047$ using Chi-Square analysis

${ }^{a}$ Grade I-III disc degeneration on the modified Pfirrmann classification were defined as having no high-grade degeneration, while grade IV-V were defined as having high-grade degeneration

enough. Though we observed that TK was larger in the spondylolytic group, we were unable to perform subgroup analyses on those with radicular symptoms because of the limited numbers. The observation need to be validated in a different, larger group. Third, we did not evaluate the symptom severity because back pain severity might not be proportional to image findings. Fourth, many of the subjects underwent EOS evaluation because of conscription physical examination, and were therefore male and young. Finally, MRI was only available in 33 out of the 45 patients with spondylolysis. The reduction in sample size may undermine the power of the current study.

\section{Conclusions}

In a Taiwanese population, PI and LL were significantly larger in spondylolytic patients, which is different from reports for Caucasian populations. Disc degeneration and age were associated with the occurrence of spondylolisthesis. Ethnological differences should thus be taken into account when making clinical decisions regarding spondylolysis in a Taiwanese population.

\section{Abbreviations}

PI: Pelvic incidence; SS: Sacral slope; PT: Pelvic tilt; TK:: Thoracic kyphosis; LL: Lumbar lordosis; SVA: Sagittal vertical axis; CAM: Center of acoustic meatus; T1t: T1 tilt; T9t: T9 tilt; SS: A:spinosacral angle; KE: Knee extension; CR: Computed radiography; DR: Digital radiography; CT: Computed tomography; MRI: Magnetic resonance imaging

\section{Acknowledgements}

This work was financially supported by the Medical Device Innovation Center (MDIC), National Cheng Kung University(NCKU) from the Featured Areas Research Center Program within the framework of the Higher Education Sprout Project by the Ministry of Education (MoE) in Taiwan.

\section{Authors' contributions}

YH Tseng and HC Chuang developed the study design, performed the statistical data analysis and interpretation, and were major contributors in writing the manuscript. CL Lin supervised the project and revised the manuscript. Y Chen revised the manuscript. PH Chou revised the manuscript. WL Chang revised the manuscript. PF Su revised the manuscript. All authors read and approved the final manuscript.

\section{Funding}

This work was financially supported by the Medical Device Innovation Center (MDIC), National Cheng Kung University (NCKU) from the Featured Areas Research Center Program within the framework of the Higher Education Sprout Project by the Ministry of Education (MoE) in Taiwan.

\section{Availability of data and materials}

The datasets generated and analyzed during this study are available from the corresponding author on reasonable request.

\section{Declarations}

Ethics approval and consent to participate

The study was conducted in agreement with the ethical standards of the institutional and national research committee and with the 1964 Helsinki Declaration and its later amendments. We consulted extensively with the IRB of National Cheng Kung University Hospital who determined that our study did not need ethical approval or informed consent. An IRB official waiver of ethical approval was granted from the IRB of National Cheng Kung University Hospital. (No. B-ER-106-210)

\section{Consent for publication}

Not applicable.

\section{Competing interests}

The authors declare that they have no competing interests.

\section{Author details}

'Department of Orthopaedic Surgery, National Cheng Kung University Hospital, College of Medicine, National Cheng Kung University, No.138, Sheng-Li Road, 70428 Tainan, Taiwan. ' ${ }^{2}$ Department of Plastic Surgery, Kaohsiung Veterans General Hospital, Kaohsiung, Taiwan. ${ }^{3}$ Department of Orthopaedic Surgery, Sin Lau Christian Hospital, Tainan, Taiwan. ${ }^{4}$ Department of Orthopedics and Traumatology, Taipei Veterans General Hospital, Taipei, Taiwan. ${ }^{5}$ Division of Orthopaedics, Department of Surgery, National Cheng Kung University Hospital Dou Liou Branch, National Cheng Kung University, Yunlin, Taiwan. ${ }^{6}$ Department of Statistics, National Cheng Kung University, Tainan, Taiwan. ${ }^{7}$ Skeleton Materials and Bio-compatibility Core Lab, Research Center of Clinical Medicine, College of Medicine, National Cheng Kung University Hospital, National Cheng Kung University, Tainan, Taiwan. ${ }^{8}$ Medical Device Innovation Center (MDIC), National Cheng Kung University, Tainan, Taiwan. ${ }^{9}$ Musculoskeletal Research Center, Innovation Headquarter, National Cheng Kung University, Tainan, Taiwan.

Received: 8 February 2021 Accepted: 28 May 2021

Published online: 18 June 2021

\section{References}

1. Roussouly P, Gollogly S, Berthonnaud E, Labelle H, Weidenbaum M: Sagittal alignment of the spine and pelvis in the presence of L5-S1 isthmic lysis and low-grade spondylolisthesis. Spine 2006, 31(21):2484-2490.

2. Labelle H, Roussouly P, Berthonnaud E, Transfeldt E, O'Brien M, Chopin D, Hresko T, Dimnet J: Spondylolisthesis, pelvic incidence, and spinopelvic balance: a correlation study. Spine 2004, 29(18):2049-2054.

3. Curylo LJ, Edwards C, DeWald RW: Radiographic markers in spondyloptosis: implications for spondylolisthesis progression. Spine 2002, 27(18):2021-2025.

4. Hanson DS, Bridwell KH, Rhee JM, Lenke LG: Correlation of pelvic incidence with low- and high-grade isthmic spondylolisthesis. Spine 2002, 27(18): 2026-2029.

5. Duval-Beaupère G, Schmidt C, Cosson P: A barycentremetric study of the sagittal shape of spine and pelvis: The conditions required for an economic standing position. Annals of Biomedical Engineering 1992, 20(4):451-462.

6. Jablonska-Sudol K, Maciejczak A: Relationship between the spino-pelvic parameters and the slip grade in isthmic spondylolisthesis. Neurologia i neurochirurgia polska 2015, 49(6):381-388.

7. Min WK, Lee CH: Comparison and correlation of pelvic parameters between low-grade and high-grade spondylolisthesis. Journal of spinal disorders \& techniques 2014, 27(3):162-165.

8. Oh SK, Chung SS, Lee CS: Correlation of pelvic parameters with isthmic spondylolisthesis. Asian spine journal 2009, 3(1):21-26.

9. Yin J, Peng BG, Li YC, Zhang NY, Yang L, Li DM: Differences of Sagittal Lumbosacral Parameters between Patients with Lumbar Spondylolysis and Normal Adults. Chinese medical journal 2016, 129(10):1166-1170.

10. Szypryt EP, Twining P, Mulholland RC, Worthington BS: The prevalence of disc degeneration associated with neural arch defects of the lumbar spine assessed by magnetic resonance imaging. Spine 1989, 14(9):977-981. 
11. Lai Q, Gao T, Lv X, Liu X, Wan Z, Dai M, Zhang B, Nie T: Correlation between the sagittal spinopelvic alignment and degenerative lumbar spondylolisthesis: a retrospective study. BMC musculoskeletal disorders 2018, 19(1):151.

12. Oh YM, Choi HY, Eun JP: The Comparison of Sagittal Spinopelvic Parameters between Young Adult Patients with L5 Spondylolysis and Age-Matched Control Group. Journal of Korean Neurosurgical Society 2013, 54(3):207-210.

13. Oh YM, Eun JP: The relationship between sagittal spinopelvic parameters and the degree of lumbar intervertebral disc degeneration in young adult patients with low-grade spondylolytic spondylolisthesis. The bone \& joint journal 2013, 95-b(9):1239-1243.

14. Zhu Z, Xu L, Zhu F, Jiang L, Wang Z, Liu Z, Qian BP, Qiu Y: Sagittal alignment of spine and pelvis in asymptomatic adults: norms in Chinese populations. Spine 2014, 39(1):E1-6.

15. Deschenes S, Charron G, Beaudoin G, Labelle H, Dubois J, Miron MC, Parent $S$ : Diagnostic imaging of spinal deformities: reducing patients radiation dose with a new slot-scanning X-ray imager. Spine 2010, 35(9):989-994.

16. Tyrakowski M, Yu H, Siemionow K: Pelvic incidence and pelvic tilt measurements using femoral heads or acetabular domes to identify centers of the hips: comparison of two methods. European Spine Journal 2015, 24(6):1259-1264.

17. Janusz P, Tyrakowski M, Monsef JB, Siemionow K: Influence of lower limbs discrepancy and pelvic coronal rotation on pelvic incidence, pelvic tilt and sacral slope. European Spine Journal 2016, 25(11):3622-3629.

18. Tyrakowski M, Wojtera-Tyrakowska D, Siemionow K: Influence of pelvic rotation on pelvic incidence, pelvic tilt, and sacral slope. Spine 2014, 39(21): E1276-1283.

19. Vialle R, Levassor N, Rillardon L, Templier A, Skalli W, Guigui P: Radiographic analysis of the sagittal alignment and balance of the spine in asymptomatic subjects. The Journal of bone and joint surgery American volume 2005, 87(2):260-267

20. Ohrt-Nissen S, Cheung JPY, Hallager DW, Gehrchen M, Kwan K, Dahl B, Cheung KMC, Samartzis D: Reproducibility of thoracic kyphosis measurements in patients with adolescent idiopathic scoliosis. Scoliosis Spinal Disord 2017, 12:4.

21. Chen HY, Yang MH, Lin YP, Lin FH, Chen PQ, Hu MH, Yang SH: Impact of cervical sagittal parameters and spinal cord morphology in cervical spondylotic myelopathy status post spinous process-splitting laminoplasty. European spine journal: official publication of the European Spine Society, the European Spinal Deformity Society, and the European Section of the Cervical Spine Research Society 2020, 29(5):1052-1060.

22. Griffith JF, Wang YX, Antonio GE, Choi KC, Yu A, Ahuja AT, Leung PC: Modified Pfirrmann grading system for lumbar intervertebral disC degeneration. Spine 2007, 32(24):E708-712.

23. Floman Y: Progression of lumbosacral isthmic spondylolisthesis in adults. Spine 2000, 25(3):342-347.

24. Asai Y, Tsutsui S, Oka H, Yoshimura N, Hashizume H, Yamada H, Akune T, Muraki S, Matsudaira K, Kawaguchi H et al: Sagittal spino-pelvic alignment in adults: The Wakayama Spine Study. PloS one 2017, 12(6):e0178697.

25. Lee CS, Chung SS, Kang KC, Park SJ, Shin SK: Normal patterns of sagittal alignment of the spine in young adults radiological analysis in a Korean population. Spine 2011, 36(25):E1648-1654.

26. Vaz G, Roussouly P, Berthonnaud E, Dimnet J. Sagittal morphology and equilibrium of pelvis and spine. European spine J. 2002;11(1):80-7.

27. Vialle $R$, Ilharreborde B, Dauzac C, Lenoir T, Rillardon L, Guigui P: Is there a sagittal imbalance of the spine in isthmic spondylolisthesis? A correlation study. European spine journal: official publication of the European Spine Society, the European Spinal Deformity Society, and the European Section of the Cervical Spine Research Society 2007, 16(10):1641-1649.

28. Yukawa Y, Kato F, Suda K, Yamagata M, Ueta T, Yoshida M: Normative data for parameters of sagittal spinal alignment in healthy subjects: an analysis of gender specific differences and changes with aging in 626 asymptomatic individuals. European spine journal: official publication of the European Spine Society, the European Spinal Deformity Society, and the European Section of the Cervical Spine Research Society 2018, 27(2):426-432.

29. Trejaut JA, Poloni ES, Yen JC, Lai YH, Loo JH, Lee CL, He CL, Lin M: Taiwan Ychromosomal DNA variation and its relationship with Island Southeast Asia. BMC Genet 2014, 15:77.

30. Stagnara P, De Mauroy JC, Dran G, Gonon GP, Costanzo G, Dimnet J, Pasquet $A$ : Reciprocal angulation of vertebral bodies in a sagittal plane: approach to references for the evaluation of kyphosis and lordosis. Spine 1982, 7(4):335-342.

31. Legaye J, Duval-Beaupere G: Sagittal plane alignment of the spine and gravity: a radiological and clinical evaluation. Acta orthopaedica Belgica 2005, 71(2):213-220.

32. Lonner BS, Auerbach JD, Sponseller P, Rajadhyaksha AD, Newton PO: Variations in pelvic and other sagittal spinal parameters as a function of race in adolescent idiopathic scoliosis. Spine 2010, 35(10):E374-377.

33. Dai LY: Disc degeneration in patients with lumbar spondylolysis. Journal of spinal disorders 2000, 13(6):478-486.

34. Gervais J, Perie D, Parent S, Labelle H, Aubin CE: MRI signal distribution within the intervertebral disc as a biomarker of adolescent idiopathic scoliosis and spondylolisthesis. BMC musculoskeletal disorders 2012, 13:239.

35. McCunniff PT, Yoo H, Dugarte A, Bajwa NS, Toy JO, Ahn UM, Ahn NU: Bilateral Pars Defects at the L4 Vertebra Result in Increased Degeneration When Compared With Those at L5: An Anatomic Study. Clinical orthopaedics and related research 2016, 474(2):571-577.

36. Wang F, Cai F, Shi R, Wang XH, Wu XT: Aging and age related stresses: a senescence mechanism of intervertebral disc degeneration. Osteoarthritis and cartilage 2016, 24(3):398-408.

37. Kalichman L, Kim DH, Li L, Guermazi A, Berkin V, Hunter DJ: Spondylolysis and spondylolisthesis: prevalence and association with low back pain in the adult community-based population. Spine 2009, 34(2):199-205.

38. Oh CH, Yoon SH: Whole Spine Disc Degeneration Survey according to the Ages and Sex Using Pfirrmann Disc Degeneration Grades. Korean Journal of Spine 2017, 14(4):148-154

39. Rousseau MA, Laporte S, Chavary-Bernier E, Lazennec JY, Skalli W: Reproducibility of measuring the shape and three-dimensional position of cervical vertebrae in upright position using the EOS stereoradiography system. Spine 2007, 32(23):2569-2572.

40. Wybier M, Bossard P: Musculoskeletal imaging in progress: the EOS imaging system. Joint, bone, spine: revue du rhumatisme 2013, 80(3):238-243.

\section{Publisher's Note}

Springer Nature remains neutral with regard to jurisdictional claims in published maps and institutional affiliations.

Ready to submit your research? Choose BMC and benefit from

- fast, convenient online submission

- thorough peer review by experienced researchers in your field

- rapid publication on acceptance

- support for research data, including large and complex data types

- gold Open Access which fosters wider collaboration and increased citations

- maximum visibility for your research: over $100 \mathrm{M}$ website views per year

At $\mathrm{BMC}$, research is always in progress.

Learn more biomedcentral.com/submissions 